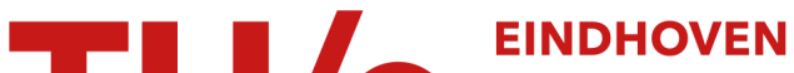 \\ UNIVERSITY OF \\ TECHNOLOGY
}

\section{Research through design: a camera case study}

Citation for published version (APA):

Frens, J. W. (2007). Research through design: a camera case study. In R. Michel (Ed.), Design research now : essays and selected projects (pp. 135-156). (Board of International Research in Design). Birkhäuser Verlag. https://doi.org/10.1007/978-3-7643-8472-2_9

DOI:

10.1007/978-3-7643-8472-2_9

Document status and date:

Published: 01/01/2007

\section{Document Version:}

Publisher's PDF, also known as Version of Record (includes final page, issue and volume numbers)

\section{Please check the document version of this publication:}

- A submitted manuscript is the version of the article upon submission and before peer-review. There can be important differences between the submitted version and the official published version of record. People interested in the research are advised to contact the author for the final version of the publication, or visit the $\mathrm{DOI}$ to the publisher's website.

- The final author version and the galley proof are versions of the publication after peer review.

- The final published version features the final layout of the paper including the volume, issue and page numbers.

Link to publication

\section{General rights}

Copyright and moral rights for the publications made accessible in the public portal are retained by the authors and/or other copyright owners and it is a condition of accessing publications that users recognise and abide by the legal requirements associated with these rights.

- Users may download and print one copy of any publication from the public portal for the purpose of private study or research.

- You may not further distribute the material or use it for any profit-making activity or commercial gain

- You may freely distribute the URL identifying the publication in the public portal.

If the publication is distributed under the terms of Article $25 f a$ of the Dutch Copyright Act, indicated by the "Taverne" license above, please follow below link for the End User Agreement:

www.tue.nl/taverne

Take down policy

If you believe that this document breaches copyright please contact us at:

openaccess@tue.nl

providing details and we will investigate your claim. 


$$
\begin{aligned}
& \text { Research through } \\
& \text { Design: a Camera } \\
& \text { Case Study "' }
\end{aligned}
$$


Information-for-use has become abstracted from human skills during the rise of interactive products. This chapter describes the search for a new interaction paradigm for interactive products, applying a research through design approach. Five conceptual cameras were designed to explore the solution domain for this new paradigm, named rich interaction. One of the proposals was elaborated into a modular, working prototype. The prototype accepts different interface modules to vary the interaction style of the camera from rich to conventional. In an experiment the interaction styles were compared. 


\section{Introduction}

This article focuses on highly interactive products. Such products can be seen as having three properties: form, interaction and function. FIG. ${ }^{01}$ Central to this model is the notion that these properties are related to each other. For form invites interaction, and in this interaction functionality is achieved.

When we compare interactive products to more traditional non-interactive products we see that they differ in how they provide information-for-use. During the rise of interactive products, information-for-use gradually became more and more abstract. For example, a person can directly perceive what a drinking glass is for, and how it can be used, from its form. The information-for-use is a natural consequence of form and use, and thus is directly available. In contrast, a person needs to read and interpret the labels on the controls of a digital camera to understand what he or she can do with it. In this case the information-for-use is much more abstract. There is a difference in how people's skills are addressed. Overbeeke et al. identify three types of human skills that are relevant in this context: perceptualmotor, emotional and cognitive skills. ${ }^{[02]}$ Where the earlier products address all of people's skills, the new electronic interactive products mainly address people's cognitive skills. The focus of interaction with products has shifted from an action-based paradigm to a cognition-based one.

The reason for this shift is that the design of the form and interaction are explicitly separated. In interactive products, a designer is free to choose which controls to use on their interfaces. The controls on the interfaces are not determined by the functional components, but are coupled to electronic hardware through programming. At the same time, designers of interactive products have virtually complete freedom of form. The functional components of interactive products have become so small that they no longer impose a form. Electronics give designers freedom, not only because they are small but also because a designer is free to choose how to control them. With the advent of electronics the 'real' interface was born and interaction style was now 'designable'. This fact made it possible to design the form of electronic products separately from the interaction.

When we regard state-of-the-art interactive products it is striking to see that form is richly varied but interaction is standardised. In fact, design of interaction is heavily influenced by design principles borrowed from the human-computer interaction $(\mathrm{HCl})$ community. ${ }^{\text {[03] }}$ For products to offer information-for-use inspired by function and interaction they need to be opened up for all human skills. I believe that the design process of interactive electronic products needs to be adapted to accomplish this. I propose an integral design process for interactive products, inspired by the traditional design process; one where form, interaction and function are explored and designed concurrently in order to integrate them into dedicated interactive products; a design process where information-for-use is inspired by function, and where human skills are central to interaction. But before considering this further, I first explain my research approach and address my research question. 


\section{Approach and research question}

In this article I explore new interaction paradigms for interactive consumer products. I choose to do this in a typically designerly manner, by designing interactive products, by conducting research through design.

\section{Research through design}

Research through design is similar to Archer's 'research through practice.' ${ }^{[04]}$ Archer recognises research through practice as a form of action research, which he defines as 'Action Research: Systematic investigation through practical action calculated to devise or test new information, ideas, forms or procedures and to produce communicable knowledge', ${ }^{[04]}$ p. 6. He warns that since action research is situation-specific it is 'difficult and dangerous to generalise from Action Research findings', ${ }^{[04]}$ p. 12. What is important in this statement is the word: 'situation-specific'. For me this implies two things. First, the skills of the designer play an important role; it is through the designerly skills that the problem area unfolds. Second, the knowledge gained through a research through practice project is applicable to a specific situation. Or as Hummels states, it leads 'to conditional laws instead of general laws'. ${ }^{[05]}$ In the case of design it is applicable to a specific class of products and its design process. Archer states that a practitioner should position himself in opinion and theory concerning the domain in which the knowledge from his research is applicable. ${ }^{[04]}$

Knowledge on two levels can be gathered when researching product design. We can research aspects of the products themselves, such as form or interface, but we can also research the process of how these products came into existence. When conducting research through design, both types of knowledge are intertwined. Knowledge of products and knowledge of the process of designing these products are generated. Products are designed to explore the implications of theory in context. The resulting products are subjected to experimentation in reallife situations to understand the complex relationship of humans and designed reality. The assumption underlying the research-through-design approach is that knowledge gained from these products, through experimentation, can be generalised in the form of design specifications for future products and in new theory or frameworks.

\section{Four questions and answers}

This article is organised around four questions. First, what will be the basis for this alternative interaction paradigm? Second, what is the solution domain of this new interaction paradigm? Third, how does such a new interaction paradigm compare to the old one? Fourth, how can this new paradigm be characterised? Here these questions are answered in a designerly manner, doing research through design. The first question is answered by taking position in theory, the second by designing, the third through experimentation, and finally, the fourth question is answered in a reflection on the answers to the first three. 
To answer the first question I position myself in theory. ${ }^{[04]}$ Two areas of research form the background for the new interaction paradigm explored in this research: the area of tangible interaction ${ }^{[06,07]}$ and the theory of direct perception. ${ }^{[08]}$ Tangible interaction is one of the few $\mathrm{HCl}$ interaction styles concerned with the physical. It involves the use of physical objects to interact with computer systems, offers function-specific interfaces, and involves more human skills than only cognitive ones. Tangible interaction offers opportunities for embodied interaction. ${ }^{[09]}$ The theory of direct perception (particularly the notion of affordances) provides deeper insight into how information-for-use can be given.

\section{Rich interaction}

Inspired by tangible interaction and the concept of affordances I propose the term 'rich interaction'. This is a new interaction paradigm for interactive consumer products. Tangible interaction inspires the use of 'action-driven' interaction, while the concept of affordances inspires and steers the usage of information-for-use. Respecting and starting from people's skills, rich interaction aims for aesthetic interaction through a unity of form, interaction and function. In more detail this means:

- Starting from people's skills: Information-for-use relates directly to all human skills (perceptual-motor, emotional and cognitive skills), instead of abstractly to cognitive skills alone.

- Aiming for aesthetic interaction: Several researchers in the area of design-related research pursue something that they have dubbed 'aesthetic interaction' [05, 10, 11, 12, 13]. Opinions differ on what aesthetic interaction is. For now I propose to use the working definition: 'aesthetic interaction is the aesthetic experience that only can be had while interacting.'

- Integrating form, interaction and function: In the introduction I mentioned three properties of interactive products; form, interaction and function. In traditional artefacts these properties are strongly and meaningfully related. For example, the form of a hammer invites interaction: we can grab the shaft to swing the hammer. In this interaction with the hammer its functionality is reached: hammering nails into pieces of wood. The form of the hammer not only invites us to hammer, it also expresses the hammer's function. The relations between form, interaction and function carry information-for-use.

In state-of-the-art interactive products there is no technical reason for these meaningful relations to exist. As a result they are eased. A product can have any form, buttons are added for interaction, and functionality is delivered in unified software platforms. However, in line with Wensveen et al., who state that form is not arbitrary, ${ }^{[14]}$ I argue for the restoration of these meaningful relations to accomplish a unity of form, interaction and function. Rich 
interaction is about inviting us to interact through form, thus achieving functionality. It is about expressing functionality in form and action-possibilities. The designerly skills of product designers are essential for accomplishing this.

Although product designers are trained in such integration in traditional products I believe that interactive products offer more aspects that need integration. I distinguish six aspects that can be explored in a design process. ${ }^{\text {FIG. } 02}$

Of course, the six fields of exploration do not all operate at the same level, and they should not be regarded in isolation. The framework demonstrates the width of the exploration space and provides handles for designing the three properties of interactive products and their relations concurrently. For example, by exploring the interplay between form and interaction (e.g. how does form invite specific interactions, how can different action-possibilities be expressed in form), the relation between the two is explored as well.

\section{Question two: what is the solution domain of this new interaction paradigm?}

\section{Exploring and demonstrating rich interaction by designing}

I explained above what rich interaction is in words. But I believe that what is meant by rich interaction is best explored and demonstrated with product designs. In 'doing design' the knowledge that is implicit in design skills is made explicit. Through the process of designing actual product concepts rich interaction is physically defined. Theory of tangible interaction and affordances is applied to the new concept in a designerly manner. The resulting product concepts are physical hypotheses to test rich interaction, which can be tested in experiments.

Five digital camera concepts were designed. FIG. 03 The design explorations were done in an experiential manner, using the framework for exploration introduced above. A combination of sketching, foam-core modelling and cardboard modelling techniques was applied, while user-actions (as part of interaction) were used as a starting point for the designs. Step-by-step combinations of form, interaction and function were researched, put into form and tested, thereby exploring all six fields and evaluating their solution domains.

The design process is an iterative one in which pre-models are built, tested and modified until they meet the requirements set by the designer. Through the cycle of building, testing and changing pre-models, the quality of the combinations was assessed in terms of aesthetics of interaction and information-for-use.

To spark the creative process of designing rich interactive cameras, five sub-themes were defined. The themes were restrictive so as to force design challenges to the surface, a common practice in creativity techniques. ${ }^{[10]}$ There was another reason for creating the themes as well. The themes were defined to cover a broad area of the potential solution domain for interaction paradigms. I tried to find a balance between real-world design problems 
FIG. 01 Three properties of interactive products

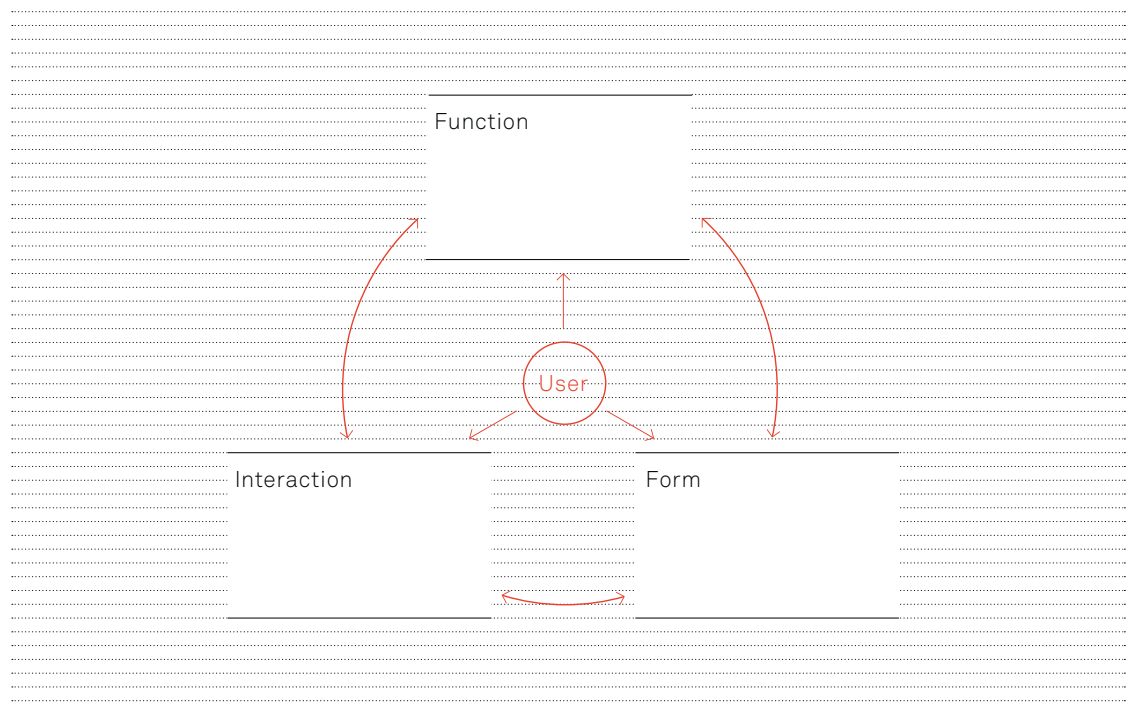

FIG.02 A framework for exploration

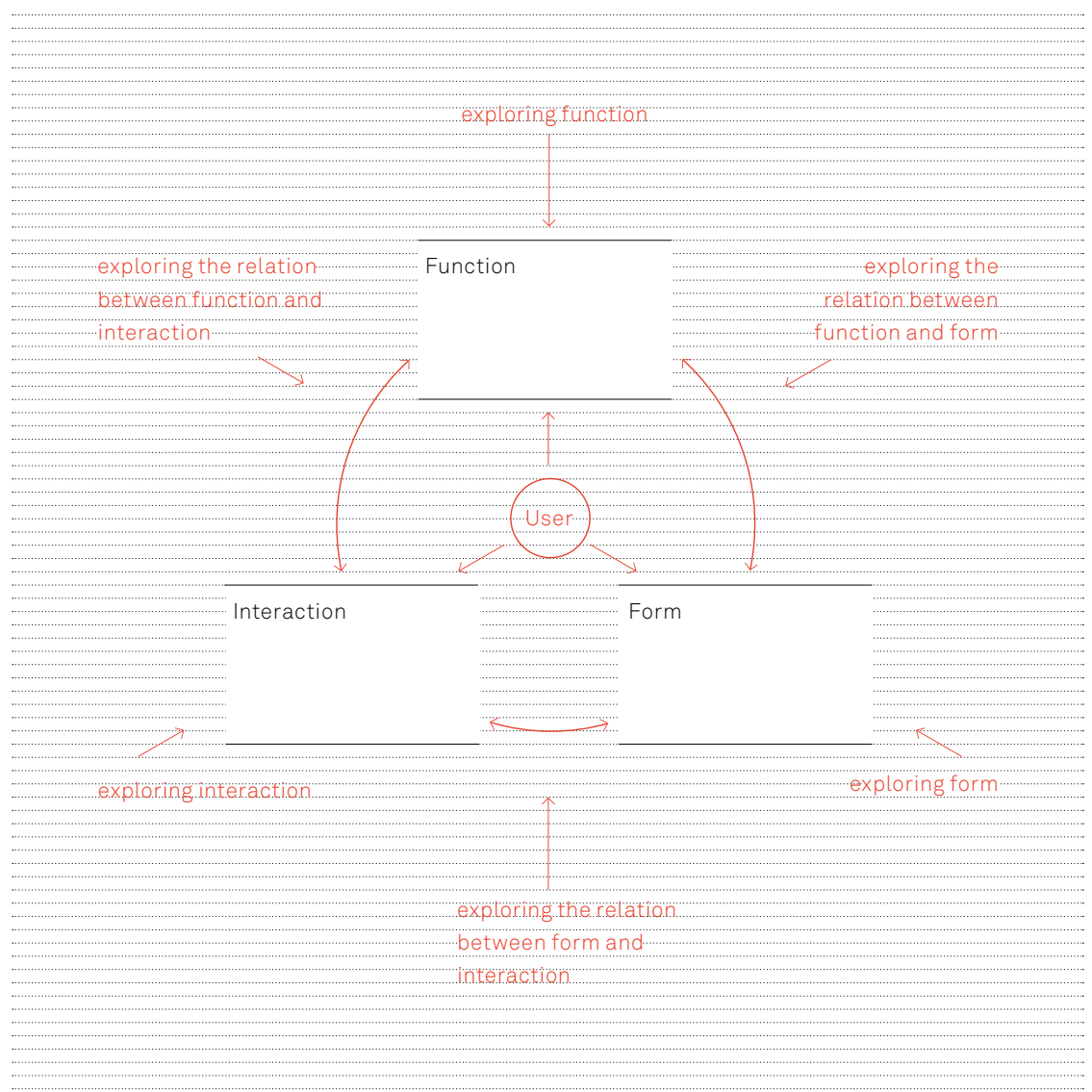


and trends in $\mathrm{HCl}$ research. They range from technology driven solutions to human-centred solutions and from the pragmatic to the unusual.

\section{Characteristics of rich interaction}

While designing the five concept-cameras, I found that two typical characteristics of rich interaction kept resurfacing as a result of integrating form, interaction and function: mode-relevant action-possibilities, and mode-of-use reflected in physical state.

Mode-relevant action-possibilities (MRAPS) Mode-relevant actionpossibilities are action-possibilities that are only provided when they are relevant for the mode-of-use. They can be characterised as: (1) dedicated to a function, (2) offering meaningful integration of form and function, and (3) expressing functionality in form and interaction. For example the lever to browse saved pictures is accessible only when the 'Labelless Cam' is in view-mode. This contrasts with products with ordinary interfaces that often show all actionpossibilities all the time, even if they have no function. FIG. 04

Mode of use reflected in physical state (MURPS) To reflect the mode-of-use in the physical state means that in each mode-of-use the form of a product is different. MURPS can be characterised as: (1) offering integration of form and function, and (2) offering autonomy (symmetry) in product behaviour in relation to user actions. For example, the 'Control per Function Cam' looks different when in camera mode than when in viewmode. This differs from ordinary interfaces, which commonly do not change shape, but always have the same form. ${ }^{\text {IIG. } 05}$

\section{Explorative user study}

The 'camera without labels on its controls'FlG. 03 was chosen for use in a first, explorative experiment because it fitted the theoretical background of this research-through-design project best. Moreover, it integrated the two typical characteristics most beautifully. From here on this camera is referred to as the Rich Interactive Camera (RUI camera). It was compared with a more traditional camera in terms of intuitiveness of interaction. For this experiment, two cardboard mock-ups of the digital cameras were used. Two main conclusions were drawn from the experiment.

First, to assess the quality of an interaction style, we need working, interactive prototypes. Interaction is an intangible quality of products, which is present only while interacting. Imagined interaction is not interaction. The consequence of this is obviously that to assess the quality of rich interaction a working, interactive prototype of the camera needs to be built.

Second, people were unable to compare the use of the cameras because the difference in form was an obstacle. The form of the cameras proved to suggest different contexts of use, 


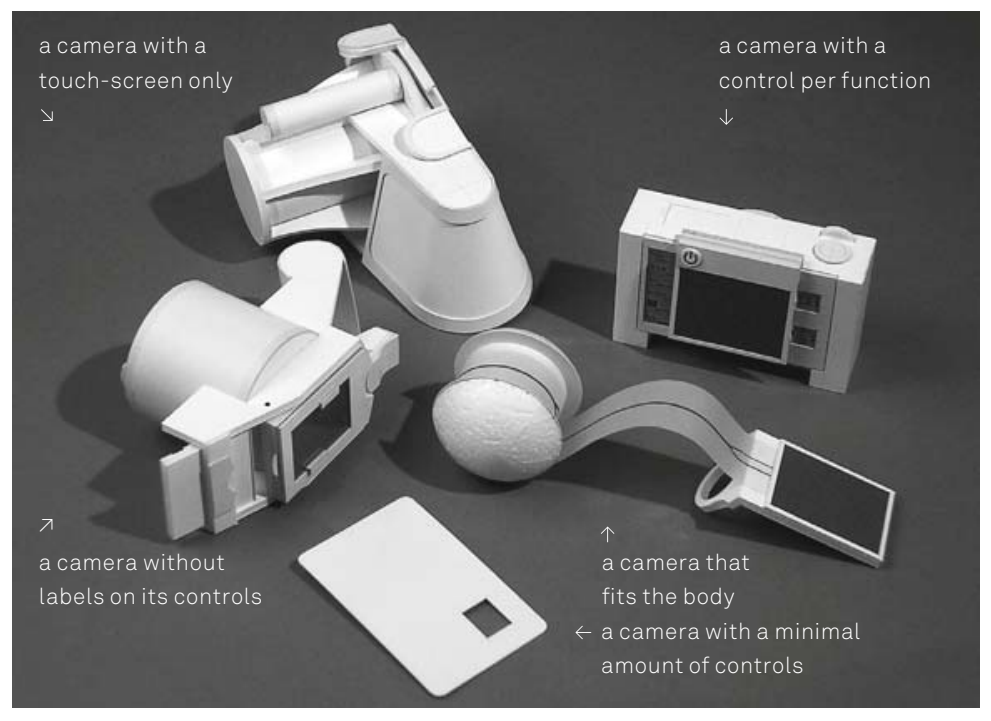

FIG. 04 Mode-relevant action-possibilities

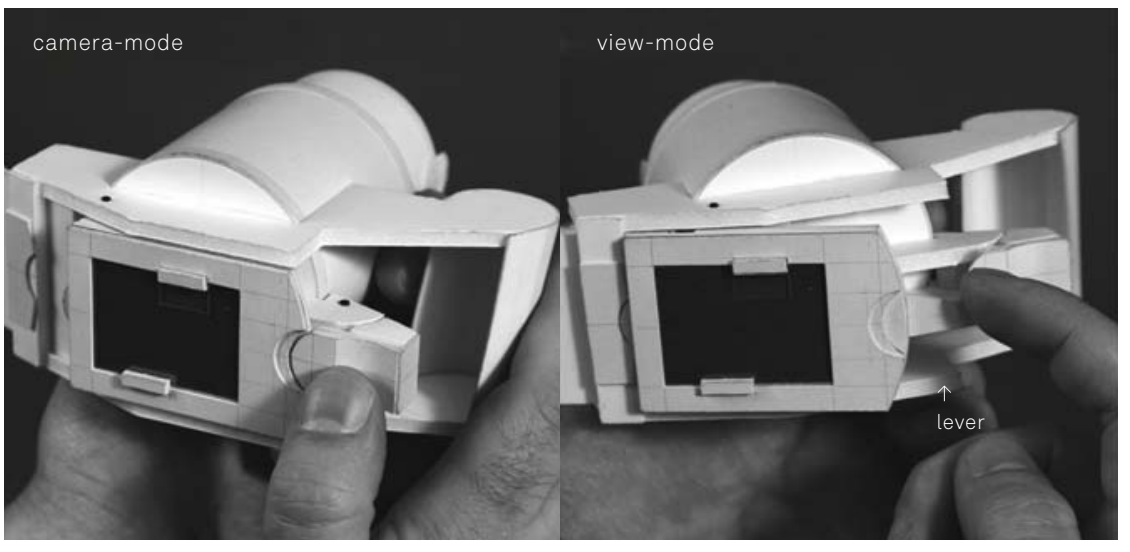

all action-possibilities

always visible

FIG. 05 Mode-of-use reflected in physical state

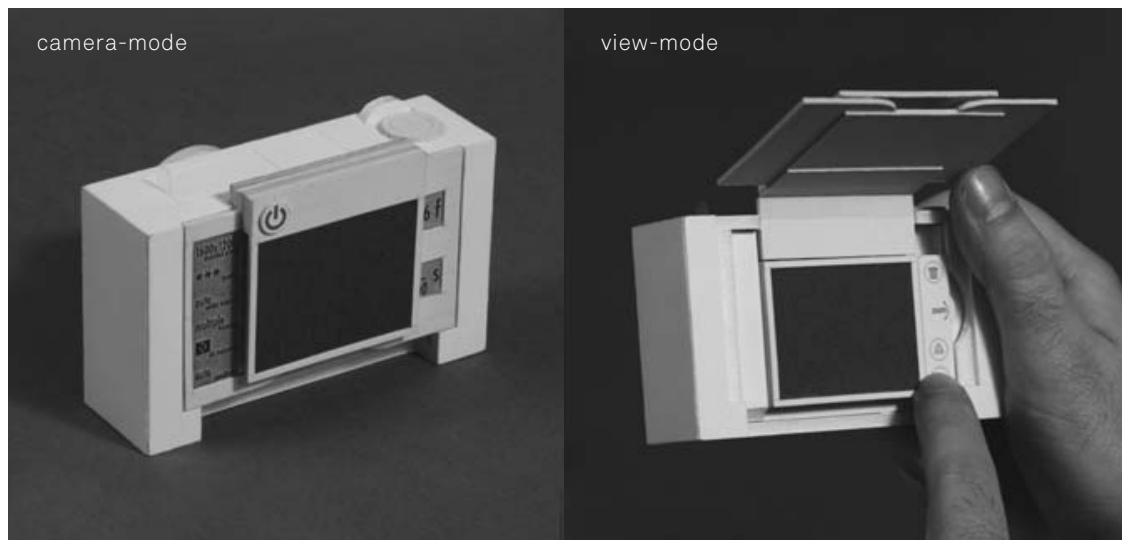

same form in each

mode-of-use

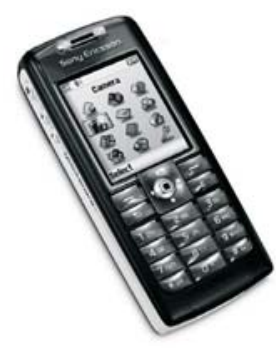


and thus to imply different interaction possibilities. To minimise the influence of form it should be the same for each camera compared. That is, the form of the cameras should be as similar as possible, while the interaction style of the cameras is varied.

This means that to compare the rich interaction style with a more conventional interaction style experimentally, we need working prototypes that have the same form as far as possible. To accomplish this I decided to build a modular working prototype of the digital camera, so that it can accept different interface modules, each reflecting different interaction styles.

\section{Working prototype with interface modules}

The design of the digital camera was slightly adapted for reasons of modularity and manufacturability. The design was also scaled up 125 per cent to fit the functional parts. The workings of the digital camera are based on a commercially available camera. The body of the camera and the interface modules were machined out of aluminium. ${ }^{\text {IG. } 06}$

Modules Above,lidentified two typical characteristics of rich interaction that resulted from the integration of form, interaction, and function; 'mode-relevant action-possibilities' (MR APS) and 'mode-of-use reflected in physical state' (MURPS). These two characteristics adequately describe the differences between the rich interactive camera (RUI camera) and a camera with a conventional interface. The RUI camera has both MR APs and MURPS; a conventional camera has neither. Four interface modules were designed. Each module has a different interaction style, systematically varied based on the differences between the original RUI camera and conventional digital cameras. Together, the four interface variations span a range of interaction styles from rich to conventional.FlG. 07

The four interface modules each offer the same basic functionality and have the same three modes-of-use. Pictures can be taken in 'camera-mode', and they can be played back in 'view-mode'. The camera also features a special 'instant-review-mode' in which one can choose to save or discard pictures after they are taken.

The first interface variation is the RUI camera (cell I). It provides controls that express what they are for and how they can be operated. The camera offers only the controls that are relevant for the active mode-of-use; in each of the modes-of-use it offers different actionpossibilities. It also expresses its mode-of-use in its form.

The second interface variation has MURPS but not MR APs (cell II). It provides a combination of ordinary buttons and expressive controls. Its form expresses which mode-of-use it is in, but it does not offer mode-relevant controls; instead it offers all controls all of the time.

The third interface variation has MR APs but not MURPS (cell III). Next to an ordinary button and a switch it provides a touch-sensitive surface where buttons can be projected. It offers (projected) controls only when they are relevant for the mode-of-use. Its form does not express its mode-of-use; it does not change form.

The fourth interface variation is an adaptation of a conventional camera (cell IV). It has only ordinary buttons. It offers all controls all of the time and it does not change form. 

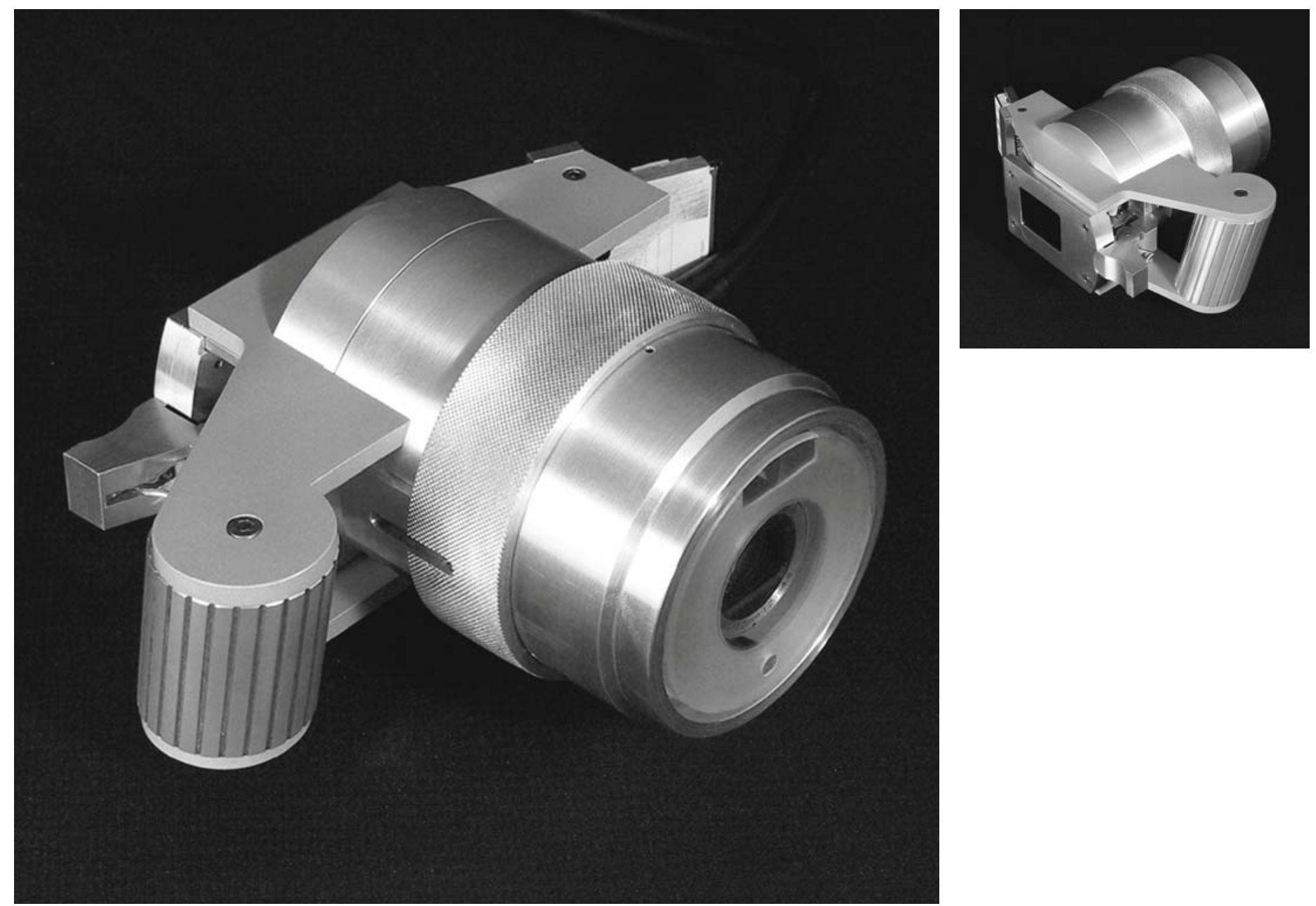

FIG. 07 Four interface variations in a grid
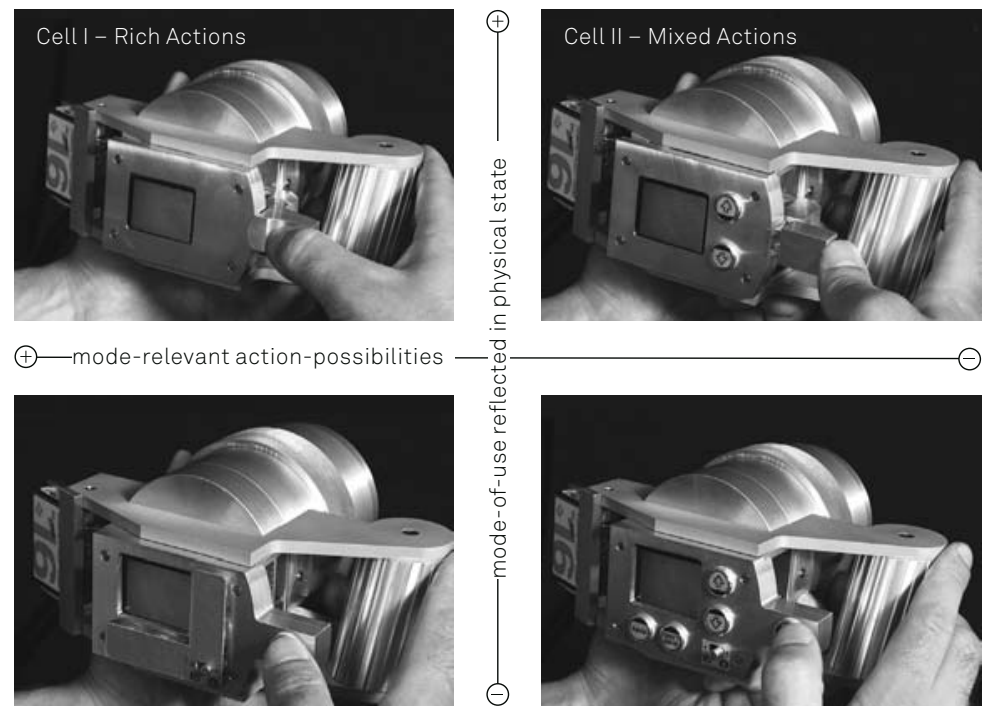
Question three: how does such a new interaction paradigm compare to the old one?

\section{Experiment}

An experiment was set up to compare the rich interaction paradigm with the more conventional interaction paradigm. The experiment is expected to provide insight into the concept of aesthetic interaction. The experiment tests the influence of MR APs and MURPS. Finally, the experiment is expected to offer insight into the relevance of HCl usability measures for the domain of interactive consumer products.

Participants Twenty-four participants, ranging in age from 19 to 29 years old, took part in the experiment. They were all students from the Architecture Department of the Eindhoven University of Technology.

Stimuli This experiment compared the four interface variations,

FIG. 07

FIG. 08

Setting The experiment took place in a photographic studio. The still-life was set up on a table and lighted by means of three studio lamps. A white line was marked on the ground $60 \mathrm{~cm}$ in front of the table. A table with video equipment, a computer and a turntable was placed in the back of the studio. Two chairs were placed at the table, one for the participant and one for the experimenter. A video camera was set up in the middle of the studio. It could be pointed at the still-life setup or at the table setup. FIG. 09

Procedure The experiment tookabout 1.5 to 2 hours per participant. During this time they each observed and used all four cameras and finally compared them. The experiment consisted of three parts.

- Part 1: The camera was observed and the AttracDif 2 questionnaire for assessing product quality was completed. ${ }^{115]}$

- Part 2: The participants were shown a training video, after which they used the camera, and completed the AttracDif 2 questionnaire again. They were given the assignment to make three beautiful pictures of the still-life. To ensure that they encountered each of the cameras' three modes-of-use they were told that they were to save only 'beautiful' pictures. Moreover, they were asked to review the pictures after they were done.

- Part 1 and 2 were repeated for each of the four cameras. When the participants were filling out the post-use questionnaire the experimenter exchanged the interface module out of view of the participants. 

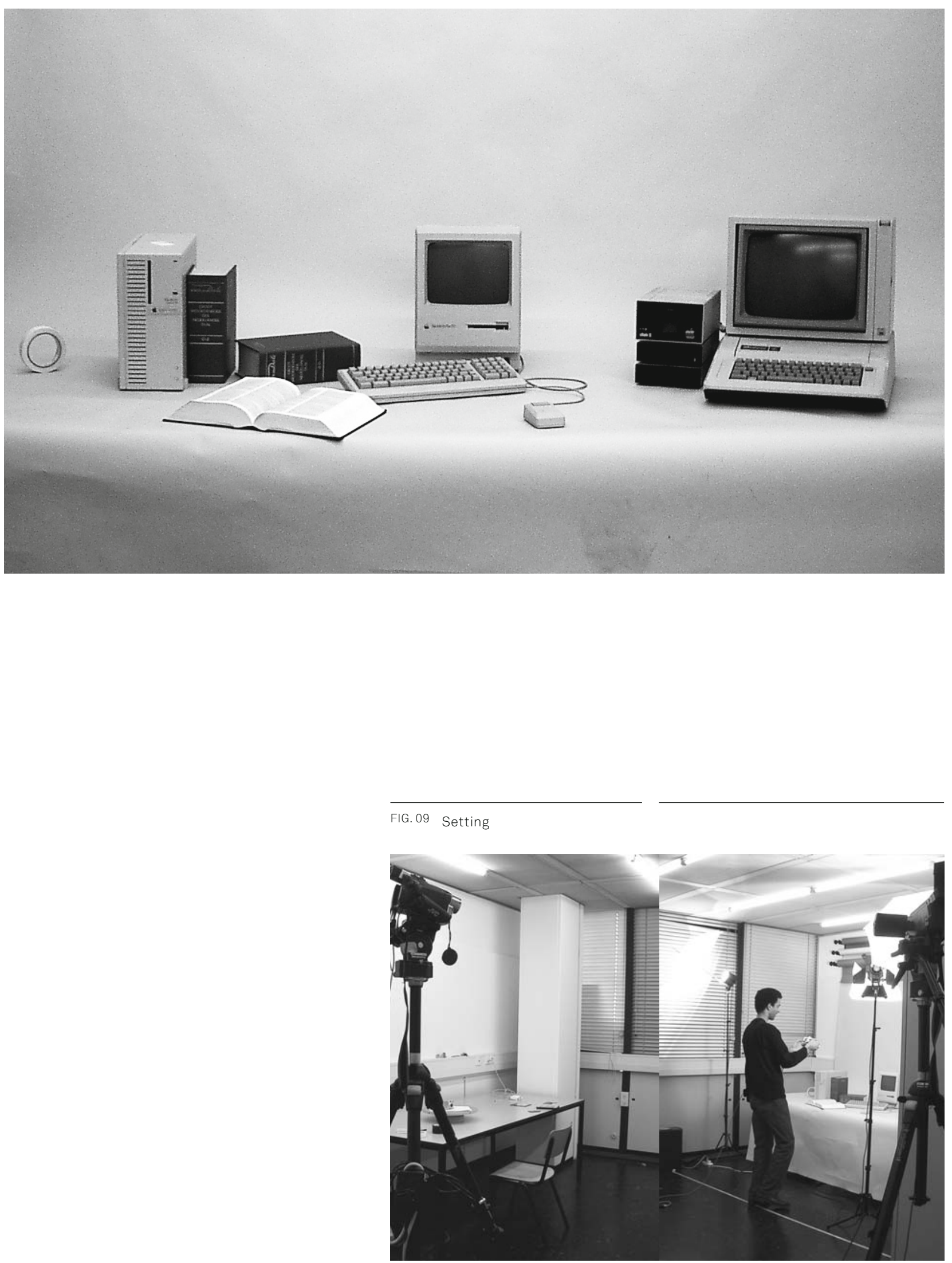
- Part 3: After four successive sessions of observing and using the cameras, the participants were asked to compare the cameras by means of a comparison questionnaire.

The order in which the four cameras were shown and used was counterbalanced. The experiment was videotaped with permission of the participants. The participants were paid $€ 7.50$ for their cooperation. Figure 10 gives an overview of the procedure.

\section{Main findings}

The results of the experiment were extensively analysed and reported. ${ }^{[01]}$ They break down into three parts.

Aesthetic interaction Analysis of the experimental results indicates that aesthetic interaction is present in the RUI camera, the camera that has both MR APs and MURPS. Moreover, it was found that 'perceived beauty' seems to influence the 'perceived goodness' of a camera, regardless of the 'perceived ease of use'. Finally, severe usability problems, hampering the functionality of a product, eliminate the presence of aesthetic interaction. It was concluded that there seemed to be different kinds of 'hard-to-use'; a kind of 'hard-to-use' that renders a product 'inoperable' and one that does not hamper the operation of a product (ineffective vs. effective).

Differentiating factors The experiment also reveals that MR APs influence the perceived ease of use positively, and that the cameras that employ MR APs are preferred over the other cameras. MURPS, on the other hand, did not seem to influence perceived ease of use or preference, positively or negatively.

Classic usability measures Finally, the RUI camera is not found to differ in efficiency and effectiveness from the conventional camera. Only one of the cameras is found to differ in these measures, the one that employs MURPS, but not MR APs. This is attributed to a usability problem that is found to be present in that camera.

\section{Summary}

In sum, it is possible to find an alternative for the conventional interaction style. The rich interaction style forms a viable alternative, yet it does not imply another standardisation of interaction style. Instead, it offers variation in interaction as a logical consequence of the variation in form and function. 
FIG. 10 Procedure of experiment

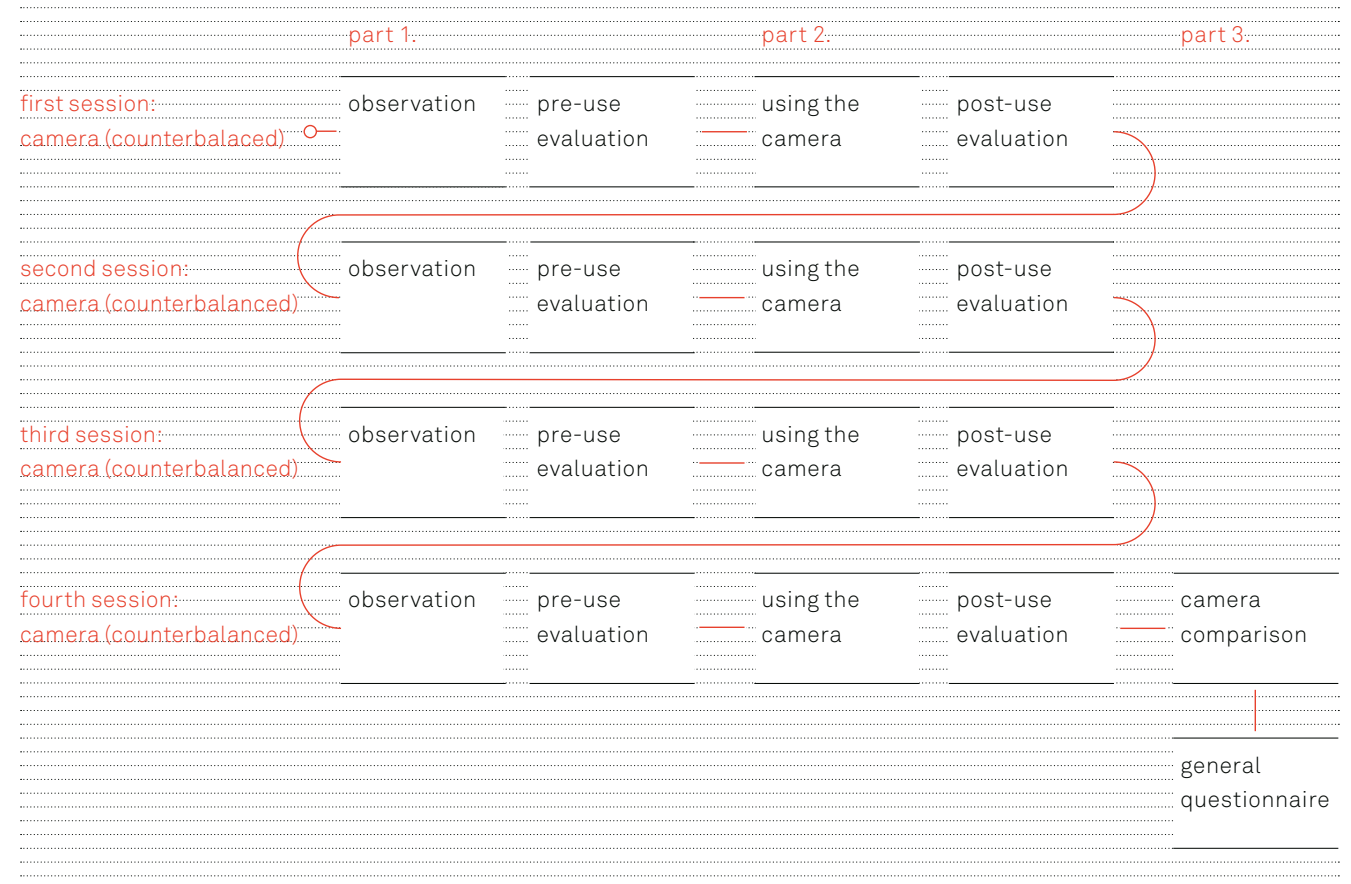


Question four: how can this new interaction paradigm

be characterised?

\section{Refined definition of rich interaction}

I set out to define, demonstrate and investigate the concept of rich interaction. In the introduction I described how information-for-use became more abstracted from human skills. A lifetime of experience with the physical world ${ }^{[07]}$ and a body that is capable of doing very refined things ${ }^{[16]}$ become obsolete. I therefore argued for providing information-for-use through form, making functionality immediately accessible (i.e. not mediated) for human skills.

I went on to describe rich interaction as 'starting from human skills, aiming for aesthetic interaction, and integrating form, interaction and function'. I also provided a 'framework for exploration' that can be used to design for rich interaction. Consequently I define rich interaction as follows:

- Rich interaction: A paradigm for interactive consumer products that results in a unity of form, interaction and function, and taps human skills (perceptual-motor, cognitive and emotional skills) for information-for-use, thereby setting the stage for aesthetic interaction.

This definition emphasises three aspects of rich interaction. I expand on each of these three aspects by reflecting on the work described here.

1. Integrating form, interaction and function Above, a 'framework for exploration' was introduced that indicated six fields of exploration that need to be explored when designing for rich interaction. I want to highlight two consequences of the integration of form, interaction and function.

- Experiential: To integrate form, interaction and function it is essential to explore the relations between them. Having decided to design for rich interaction, this needs to be done in an experiential way, as to know the quality of an interaction is to experience it. Consequently, the design process has to be taken from 2D sketching to 3D modelling practice, and from the 2D screen 'interaction simulation' to the 3D hands-on 'experience simulation'.

- Specific functionality: Unity of form, interaction and function also implies that rich interactive products are specific in the functionality they offer. This means that rich interactive products express all of their functions and action-possibilities in their form. For example, a rich interactive mobile telephone that is capable of phoning and texting also expresses both of these functions and specific action-possibilities in its form. As a consequence, changing the functionality changes the form and action-possibilities, thus changes the product. 


\section{Information-for-use inspired by human skills - affordances}

Human skills are tapped for information-for-use. Consequently the actions required to operate a rich interactive product need to be on a human scale, i.e. human skills presuppose a certain size, range and diversity. The theory of direct perception with the notion of affordances offers inspiration.

Central to my 'implementation' of the concept of affordances is the question of how to get information-for-use to the user. Herein lies the reason for my consistent use of the term 'action-possibility' instead of 'control' or 'button'. Action-possibilities suggest that they can be designed, while controls suggest that they have been designed. It is therefore necessary for designers to get out of the mindset of buttons, sliders and switches and get into the mindset of action-possibilities. Only after the action-possibilities are designed to express how to act and what will happen is there room to incorporate off-the-shelf sensors and controls.

3. Aesthetic interaction From my experience in designing, building and testing rich interactive cameras I see three prerequisites for aesthetic interaction: (1) the absence of user frustration, (2) the presence of rich action-possibilities (i.e. allowing for broad, expressive and diverse actions), and (3) the presence of other kinds of aesthetics (e.g. aesthetics of appearance, ${ }^{[17]}$ aesthetics of context, ${ }^{[05]}$ or aesthetics of narrative ${ }^{[18]}$ ). If these prerequisites are met, aesthetic interaction can be present while interacting. I identify aesthetic interaction through how it impresses the senses during interaction. Aesthetic interaction can be found in the 'feel' of rich action-possibilities.

\section{Closing remarks: Research through design}

In a research through-design-process, design methodology meets research methodology, and both contribute. Design integrates knowledge from different areas of research into relevant, highly experiential prototypes that can be seen as 'physical hypotheses'. Research offers the methods to conduct experiments and to draw knowledge from these prototypes.

I finish with a plea for design as a generator of knowledge. I have explored and defined the concept of rich interaction through the process of designing and building conceptual products. Only through building these highly experiential prototypes can the quality of interaction be assessed. Only through designing product concepts can the relevance of new ideas be tested. Designers ask different questions: what will be the use, how will it feel, why do we want that. Different questions produce different answers. Answering those questions is only possible through designing. 
Frens JW (2006) Designing for Rich Interaction: Integrating Form, Interaction, and Function. Unpublished doctoral theses, Eindhoven University of Technology, Netherlands

Overbeeke CJ, Djajadiningrat JP, Wensveen SAG, Hummels CCM (1999) Experiential and Respectful. Proceedings of the International Conference Useful and critical - The position of research in design. University of Art and Design, Helsinki

Cooper A (1999) The Inmates Are Running the Asylum. SAMS McMillan, Indianapolis

Archer B (1995) The Nature of Research. Co-Design Journal 2: 6-13

Hummels C (2000) Gestural Design Tools: Prototypes, Experiments and Scenarios. Unpublished PhD thesis, Delft University of Technology, the Netherlands

Ishii H, and Ullmer B (1997) Tangible Bits: towards Seamless Interfaces between People, Bits and Atoms. Proceedings of CHI'97, 234-241

Ullmer BA (2002) Tangible Interfaces for Manipulating Aggregates of Digital Information. Doctoral thesis, MIT, Cambridge, MA

Gibson JJ (1986) The Ecological Approach to Visual Perception. Lawrence Erlbaum, Hillsdale, $\mathrm{NJ}$

Dourish P (2004) Where the Action Is. The Foundations of Embodied Interaction. MIT Press, Cambridge, MA

Djajadiningrat JP, Gaver WW, Frens JW (2000) Interaction Relabelling and Extreme Characters: Methods for Exploring Aesthetic Interactions. Proceedings of DIS'00. New York, 66-71

Overbeeke CJ, Djajadiningrat JP, Hummels CCM, Wensveen SAG (2000) Beauty in Usability: Forget about Ease of Use! In: Green W, Jordan P (eds): Pleasure with Products, beyond Usability. Taylor and Francis, London

Graves Petersen M, Iversen OS, Krogh PG, Ludvigsen M (2004) Aesthetic Interaction - a Pragmatist's Aesthetics of Interactive Systems. Proceedings of DIS2004. Cambridge, MA, 269-276

Forlizzi J, Batterbee K (2004) Understanding Experience in Interactive Systems. Proceedings of DIS2004. Cambridge, MA, 261-268

Wensveen SAG, Overbeeke CJ, Djajadiningrat JP (2002) Push Me, Shove Me and I Show You how You Feel. Proceedings of DIS'2002. London, 335-340

Hassenzahl M (2004) The Interplay of Beauty, Goodness, and Usability in Interactive Products. Human-Computer Interaction 19: 319-349

Buur J, Jensen MV, Djajadiningrat T (2004) Hands-only Scenarios and Video Action Walls - Novel Methods for Tangible User Interaction Design. Proceedings of DIS2004. Cambridge, MA, 185-192

Locher P, Martindale C, Dorfman L, Leontiev D (2005) New Directions in Aesthetics, Creativity, and the Arts. Baywood, Amityville, NY

Dunne A, Raby F (2001) Design Noir: the Secret Life of Electronic Objects. Birkhäuser, Basel 